\title{
Second trimester rupture of an unscarred uterus following blunt trauma: a case report
}

\author{
Basil Mathews*, Chitra T. \\ Department of Obstetrics and Gynecology, Jawaharlal Institute of Post Graduate Medical Education and Research \\ (JIPMER), Puducherry, India
}

Received: 21 July 2018

Accepted: 28 August 2018

\section{*Correspondence:}

Dr. Basil Mathews,

E-mail: dr.basil_meck@hotmail.com

Copyright: ( $\odot$ the author(s), publisher and licensee Medip Academy. This is an open-access article distributed under the terms of the Creative Commons Attribution Non-Commercial License, which permits unrestricted non-commercial use, distribution, and reproduction in any medium, provided the original work is properly cited.

\section{ABSTRACT}

Uterine rupture is a life-threatening emergency in obstetrics carrying an increased risk of maternal and foetal morbidity and mortality. Often, uterus ruptures during labour; however, scarred uterus may rupture before the onset of contractions in the late third trimester. Uterine rupture in an unscarred uterus occurs extremely rare. Various aetiology has been described in literature from anomalous uterus, uterine manoeuvres, and abnormal placentation to congenital exposure to Diethylstilbestrol. Maternal outcome depends greatly on the early diagnosis, prompt management and availability of emergency expert care and blood transfusion. However, the diagnosis is not always obvious with its varied non-specific presentation. Most common presentation of rupture uterus is acute abdomen, which is often mistaken for other causes like acute pancreatitis, appendicitis, cholecystitis, especially in the early pregnancy. Authors report a case of grand multipara at 19 weeks of gestation presented as acute abdomen. She was referred as incomplete abortion in need of blood transfusion, later diagnosed to be rupture of uterus. She had abdominal pain and vaginal bleeding for 14hours duration prior to admission. On further inquiry, history of blunt trauma to abdomen, the day prior was revealed.

Keywords: Maternal morbidity, Second trimester rupture, Unscarred uterine rupture, Uterus rupture

\section{INTRODUCTION}

Rupture uterus is a catastrophic event and a surgical emergency associated with high mortality and morbidity. ${ }^{1}$ Non-labouring uterine rupture is rare and can be lifethreatening. ${ }^{2}$ Most common cause for uterine rupture is previous caesarean section and these are comparatively associated with lesser morbidity being confined to lower uterus. While the overall incidence of uterine rupture is 1 in 2000 deliveries, in an unscarred uterus it is extremely rare. While Ofir et al reported an incidence of 1 in 1700020000, study from south India including 32080 deliveries reported an incidence of $6.1 / 10,000 .^{3,4}$ Unscarred uterine rupture can be either traumatic or spontaneous. ${ }^{5,6}$ Traumatic rupture is often associated with blunt trauma abdomen while spontaneous rupture is associated with anomalous uterus and placenta accrete/percreta. ${ }^{7}$ Most common presentation is acute abdomen and is mistaken for acute pancreatitis, appendicitis, cholecystitis delaying the diagnosis. ${ }^{6}$ Symptoms of acute abdomen in pregnancy is often atypical and it would be difficult to diagnose based on clinical examination alone. Sonography aids in the diagnosis, thus facilitating the decision making and emphasising its role in modern obstetrics. ${ }^{2,8}$ Authors report a case of second trimester rupture of an unscarred uterus in multiparous women who was referred to present institute as a case of incomplete abortion. Although the patient presented with bleeding and abdominal pain, the diagnosis of rupture was not suspected until the sonographic findings suggested the same. 


\section{CASE REPORT}

A 33 years old patient, gravida 6 para 3 at 19 weeks of gestation presented with complaints of lower abdominal pain and vaginal bleeding for 14 hours duration. Patient was diagnosed to have incomplete abortion and in view of need for blood transfusion, was referred to present institute for further management. Patient gave history of increasing pain abdomen, absent foetal movements and vaginal bleeding. Her general medical history didn't reveal significant history or allergies. Her obstetrical history showed three full term deliveries with one postnatal death and two spontaneous abortions for which check curettage was done. There was no history of caesarean section or myomectomy. Current pregnancy was booked and included four visits with one first trimester ultrasound.

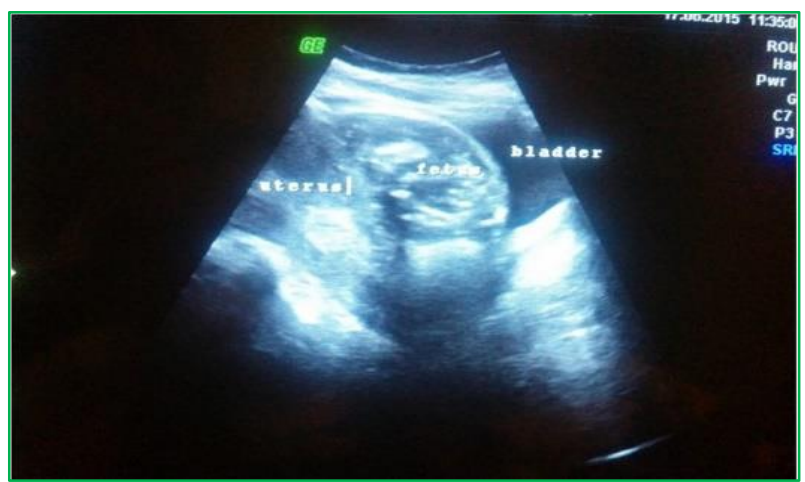

Figure 1: Ultrasound image showing empty uterus foetus seen anteriorly between bladder and anterior surface of uterine wall (intact utero-vesical fold).

Patient was haemodynamically stable with minimal suprapubic tenderness. Uterus was just palpable per abdomen and there were no peritoneal signs. Vaginal examination revealed partially effaced open cervix and bleeding from uterine cavity. Bi-manual examination revealed a bulky uterus and boggy anterior fornix. Sonographic examination showed an empty uterine cavity with foetus seen between bladder and anterior surface of uterus (Figure 1).

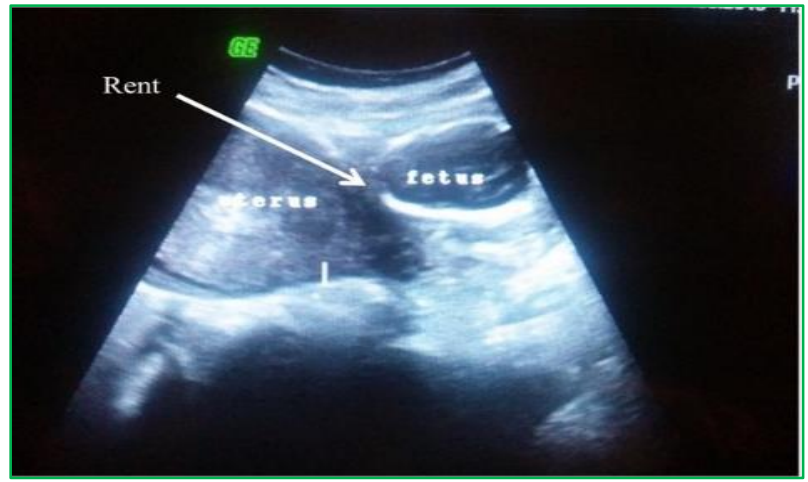

Figure 2: Rent between the foetus and uterus.
Utero-vesical (UV) peritoneal fold was intact above the foetus. Authors noted a rent between the foetus and uterus (Figure 2). No free fluid was demonstrable. On further inquiry, history of blunt trauma on abdomen by being hit by a cow was revealed. Diagnosis of Rupture uterus was made and the patient was immediately rushed for emergency laparotomy.

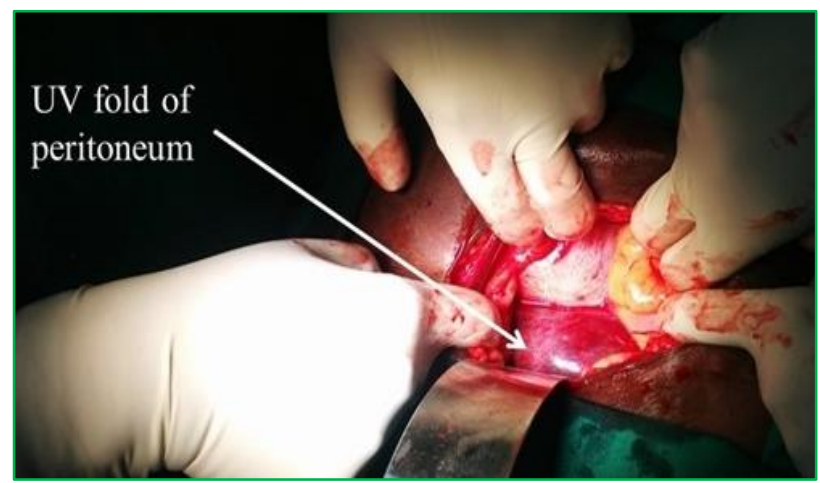

Figure 3: Intra operative image of bulging uterovesical fold filled with blood.

At the opening of abdominal wall, there was no haemoperitoneum. The UV fold was filled with blood and was bulging (Figure 3).

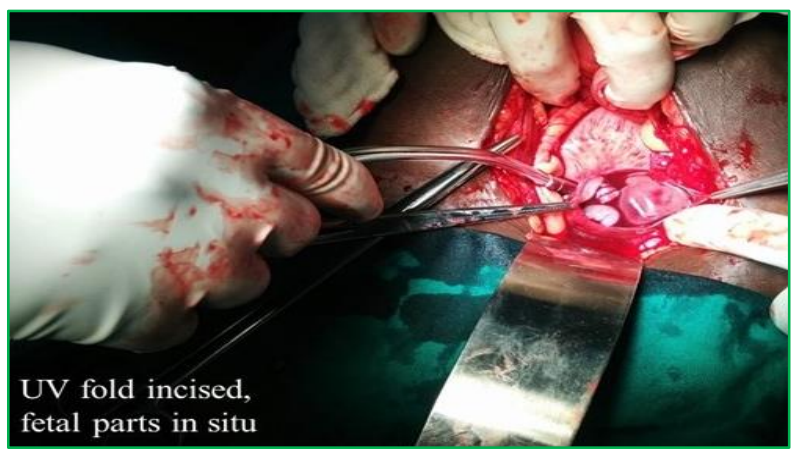

Figure 4: Intra operative image showing foetus between the uterus and bladder on opening the UV fold of peritoneum.

An incision on the UV fold was given and extracted the foetus along with placenta (Figure 4 and 5).

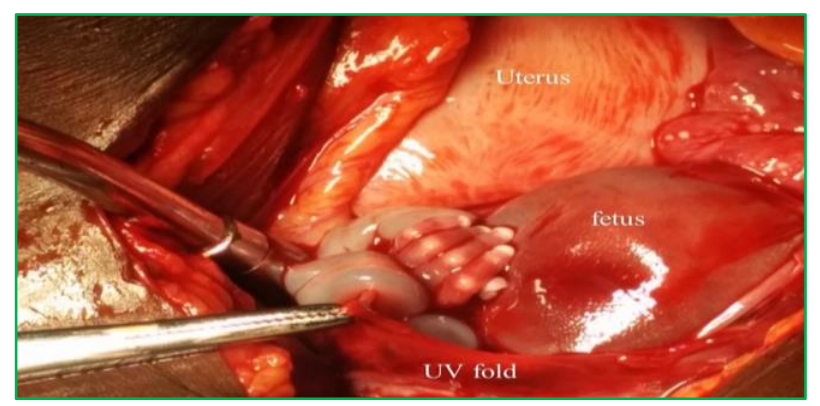

Figure 5: Intra operative image showing fetus between the uterus and bladder. 
On further inspection, a $5 \mathrm{~cm}$ rent in lower part of uterus was noted and was repaired in two layers using vicryl (Figure 6). Bilateral uterine pedicles were intact. No other complications were encountered during the surgery. Both fallopian tubes and ovaries were normal. Estimated blood loss was $1500 \mathrm{~mL}$ and patient received one packed cell transfusion. Patient received Antibiotics; Post-operative haemoglobin was $8.9 \mathrm{~g} / \mathrm{dL}$ and was discharged after seven days of hospitalization without any complication.

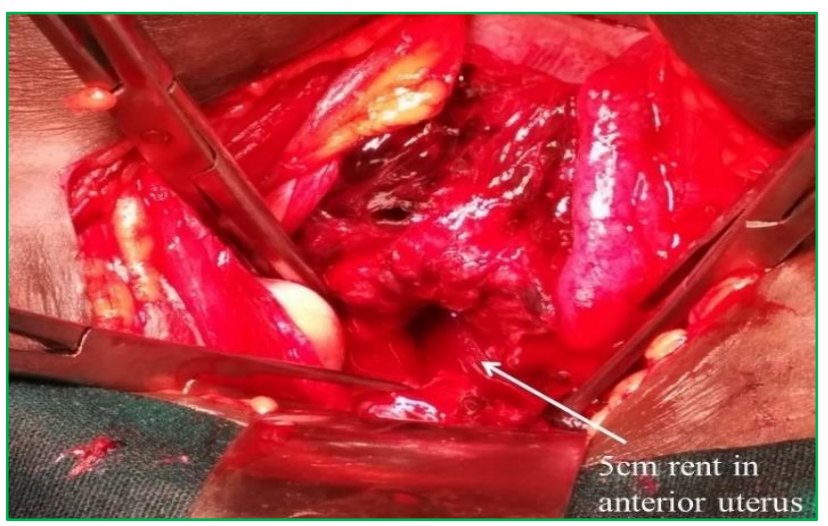

Figure 6: Rent in lower part of anterior uterus.

\section{DISCUSSION}

Uterine rupture is a life-threatening event, the risk of which depends mainly on whether uterus is scarred or not. Even though unscarred uterine rupture is the rarer variety with an incidence of $1: 17000$ to $1: 20000$ deliveries, foeto-maternal morbidity is significantly higher. ${ }^{6}$ Clinical signs of rupture are usually nonspecific and confusing thereby delaying the diagnosis and management. Associated factors for unscarred uterine rupture are trauma and obstetric manoeuvres other than possible pre-existing risk factors like grand multiparity, uterine anomaly, and abnormal placentation. ${ }^{2}$ Most common complaints at admission will be vaginal bleeding and haemodynamic instability. ${ }^{9}$

Present patient had a high parity and history of post abortal instrumental evacuation both adding as risk factors for uterine rupture. History of trauma was not revealed at presentation which delayed the diagnosis. Uterine rupture if in early pregnancy will be mistaken for ectopic pregnancy, incomplete abortion and ruptured rudimentary horn or other causes of acute abdomen like acute appendicitis, gall stones, pancreatitis etc especially if the patient is haemodynamically stable. ${ }^{10}$ All this makes diagnosis difficult but with ultrasonography, visualisation of an empty uterine cavity, protrusion of membranes at scar site or an intra peritoneal pregnancy in case of late presentation confirms the diagnosis. ${ }^{8}$ In present case the rupture being in the anterior surface and UV fold contained the bleeding helped the patient from progressing into shock. Complications of rupture are anaemia, haemodynamic shock, bladder rupture, death, infertility and vesico-vaginal fistula. Surgery related increased risk of injury to other intra-abdominal organs and hysterectomy. ${ }^{9}$

Surgical procedure will depend on the patient condition, site, size and extent of the tear. Total hysterectomy is the procedure of choice unless patient desire to preserve fertility or the patient condition warrants an immediate life-saving sub-total hysterectomy. ${ }^{9}$ Though Gibbins concluded in his study involving 146 patients that the women with primary rupture are more likely to undergo hysterectomy as compared to scarred uterus (34\% vs $2.4 \%$ ), in this case, the patient was haemodynamically stable and the rent was in the anterior surface not involving uterine pedicles thus making it amenable to repair. ${ }^{11}$ Subsequent pregnancies are at higher risk of preterm deliveries, low birth weight, cervical tears and subsequent rupture $(4-19 \%) .^{12}$

\section{CONCLUSION}

Uterine rupture can have a wide range of presentation making it a clinical diagnosis. High index of suspicion is needed at the first level of health care provider to prevent delay in diagnosis and management. Survival of the patient depends on the time interval between rupture and intervention. Timely diagnosis and prompt management can reduce the perinatal morbidity and mortality.

Funding: No funding sources

Conflict of interest: None declared

Ethical approval: Not required

\section{REFERENCES}

1. Djaković I, Rudman SS, Kosec V. Uterine rupture following myomectomy in third trimester. Acta Clin Croat. 2015;54(4):521-4.

2. Posthumus L, Donker ME. Uterine rupture in a primigravid patient, an uncommon but severe obstetrical event: A case report. J Med Case Reports. 2017; $11: 339$.

3. Ofir K, Sheiner E, Levy A, Katz M, Mazor M. Uterine rupture: differences between a scarred and an unscarred uterus. Am J Obstet Gynecol. 2004;191(2):425-9.

4. Veena P, Habeebullah S, Chaturvedula L. A review of 93 cases of ruptured uterus over a period of 2 years in a tertiary care hospital in South India. J Inst Obstet Gynaecol. 2012;32(3):260-3.

5. Egbe TO, Halle-Ekane GE, Tchente CN, Nyemb JE, Belley-Priso E. Management of uterine rupture: a case report and review of the literature. BMC Res Notes. 2016;9(1):492.

6. Guèye $M$, Mbaye $M$, Ndiaye-Guèye $M D$, KaneGuèye SM, Diouf AA, Niang MM, et al. Spontaneous uterine rupture of an unscarred uterus before labour. Case rep Obstet Gynecol [Internet] 2012;2012. 
7. Rasool M, Masroor I, Shakoor S, Munim S. Spontaneous uterine rupture at 28 weeks: A case report. JPMA J Pak Med Assoc. 2016;66(7):898-900.

8. Venkatesh KV, Harsha B. Uterine rupture at the fundus during pregnancy: a case report. Int J Reprod Contracept Obstet Gynecol. 2015;4(6):2072-3.

9. Turgut A, Ozler A, Siddik Evsen M, Ender Soydinc H, Yaman Goruk N, Karacor T, et al. Uterine rupture revisited: Predisposing factors, clinical features, management and outcomes from a tertiary care center in Turkey. Pak J Med Sci. 2013;29(3):753-7.

10. Tola EN. First trimester spontaneous uterine rupture in a young woman with uterine anomaly. Case Rep Obstet Gynecol. 2014;2014.
11. Gibbins KJ, Weber T, Holmgren CM, Porter TF, Varner MW, Manuck TA. Maternal and fetal morbidity associated with uterine rupture of the unscarred uterus. Am J Obstet Gynecol. 2015;213(3):382.e1-6.

12. Eshkoli T, Weintraub AY, Baron J, Sheiner E. The significance of a uterine rupture in subsequent births. Arch Gynecol Obstet. 2015;292(4):799-803.

Cite this article as: Mathews B, Chitra T. Second trimester rupture of an unscarred uterus following blunt trauma: a case report. Int J Reprod Contracept Obstet Gynecol 2018;7:4305-8. 